\title{
Inhibition of Human Neutrophil Elastase by Sesquiterpene Lactone Dimers from the Flowers of Inula britannicas
}

\author{
Kwan-Chul Kim ${ }^{1}$, Dae-Jung Kim ${ }^{1}$, Myung Sun Lee ${ }^{2}$, Ji Yun Seo ${ }^{2}$, Ick-Dong Yoo ${ }^{1}$, and Ik-Soo Lee ${ }^{3 *}$ \\ ${ }^{1}$ Innoskin Co., Ltd. BVC 209, Korea Research Institute of Bioscience and Biotechnology, Daejeon 34141, Republic of Korea \\ ${ }^{2}$ Department of Beauty \& Health Care, Daejeon University, Daejeon 34520, Republic of Korea \\ ${ }^{3}$ Herbal Medicine Research Division, Korea Institute of Oriental Medicine, Daejeon 34054, Republic of Korea
}

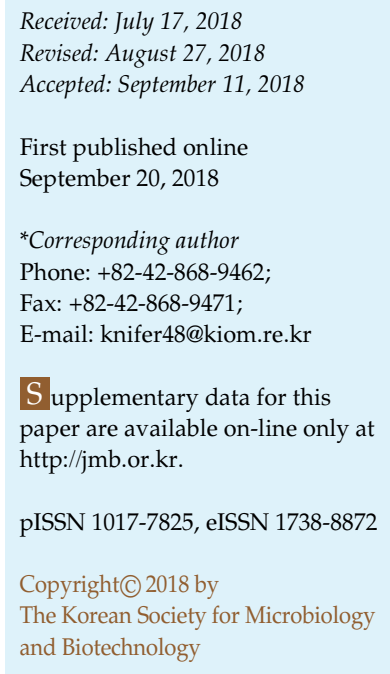

\section{Introduction}

The genus Inula belongs to the family Asteraceae, which comprises about 100 species of perennial herbs distributed across warm and temperate parts of Asia, Europe, and Africa [1]. Many Inula species have been used as traditional herbal medicines throughout the world for the treatment of bronchitis, diabetes, intestinal ulcers, digestive disorders, and inflammation [2, 3]. Among them, Inula britannica Linnaeus is one of the most commonly used plants in traditional Chinese medicine. The flowers of this plant have long been used in traditional medicine to treat digestive disorders and various types of inflammation [4], and have been shown to possess various pharmacological activities, attributable to their antimicrobial, hepatoprotective, antidiabetic, hypolipidemic, antitumor, and antiinflammatory properties [5-10]. Numerous bioactive substances, such as steroids, terpenoids (sesquiterpenes, diterpenes, and triterpenoids), phenolics, and flavonoids, have been isolated from I. britannica [11]. Of these, sesquiterpenes, and especially sesquiterpene lactones, have frequently been reported to be the active constituents, showing cytotoxic, apoptotic, and anti-inflammatory activities [10, 12-14].

In the course of searching for novel and naturally occurring inhibitors of human neutrophil elastase (HNE), we found that an EtOH extract of I. britannica flowers exhibited considerable $\mathrm{HNE}$ inhibitory activity $\left(\mathrm{IC}_{50}=\right.$ $2.68 \mu \mathrm{g} / \mathrm{ml})$. However, to date, there have been no reported studies of the HNE inhibitory activity of this plant or its secondary metabolites. Thus, we investigated the active compounds of I. britannica flowers, resulting in the isolation of a new sesquiterpene lactone dimer (1), together with five known compounds (2-6). This report describes the isolation and structural determination of these compounds, as well as the characterization of their HNE inhibitory effects.

\section{Materials and Methods}

\section{General Experimental Procedures}

Optical rotations were measured using a JASCO P-2000 digital polarimeter. The ECD spectra were measured on a JASCO J-715 
spectrometer. ${ }^{1} \mathrm{H}-(400 \mathrm{MHz})$ and ${ }^{13} \mathrm{C}-\mathrm{NMR}(100 \mathrm{MHz})$ spectra were obtained using a Bruker DRX-400 spectrometer with tetramethylsilane as an internal standard. The 2D NMR experiments (COSY, HSQC, HMBC, and NOESY) were performed on a Bruker Avance 500 NMR spectrometer. HRESIMS was performed using a Shimadzu LCMS-IT-TOF spectrometer. Column chromatography was performed using silica gel (70-230 mesh; Merck, Germany) and YMC-gel ODS-A (S-75 $\mu \mathrm{m}$; YMC, Japan). TLC was performed on pre-coated silica gel $60 \mathrm{~F}_{254}(0.25 \mathrm{~mm}$; Merck, Germany) and RP-18 $\mathrm{F}_{254 \mathrm{~s}}$ plates $(0.25 \mathrm{~mm}$; Merck, Germany). Spots were detected by UV light $(254 \mathrm{~nm})$ and spraying of $10 \% \mathrm{H}_{2} \mathrm{SO}_{4}$ followed by heating. HPLC analysis was performed on an Agilent 1200 HPLC system with a binary pump (G1312A), a vacuum degasser (G1322A), a thermostatted column compartment (G1316A), a multiple wavelength detector (G1365B, MWD), and an autosampler (G1329A) using a Luna C18 column $(250 \times 4.6 \mathrm{~mm}, 5.0 \mu \mathrm{m}$; Phenomenex, USA).

\section{Plant Material}

The flowers of I. britannica were purchased from a traditional herbal medicine store in Daejeon, Republic of Korea, in August 2016, and identified by Prof. Ki Hwan Bae (College of Pharmacy, Chungnam National University, Republic of Korea). A voucher specimen (IB2016-001) has been deposited in the Herbarium of the Korea Institute of Oriental Medicine, Republic of Korea.

\section{Extraction, Fractionation, and Isolation}

The air-dried flowers of I. britannica $(5 \mathrm{~kg})$ were extracted using $\mathrm{EtOH}(50 \mathrm{~L})$ at $80^{\circ} \mathrm{C}$ for $3 \mathrm{~h}$, filtered, and concentrated to yield an ethanol extract ( $275 \mathrm{~g}, 5.5 \%$ yield). This extract was suspended in water $(2.5 \mathrm{~L})$ and partitioned successively using $n$-hexane $(3 \times$ $2.5 \mathrm{~L})$, EtOAc $(3 \times 2.5 \mathrm{~L})$, and $n-\mathrm{BuOH}(3 \times 2.5 \mathrm{~L})$ to afford $n$ hexane- $(70 \mathrm{~g})$, EtOAc- $(110 \mathrm{~g})$, and $n-\mathrm{BuOH}$-soluble fractions $(65 \mathrm{~g})$, respectively. The EtOAc-soluble fraction $(100 \mathrm{~g})$, which significantly inhibited HNE activity, was subjected to silica gel column chromatography (70-230 mesh, $40 \times 10 \mathrm{~cm})$ and eluted with a gradient solvent system consisting of $\mathrm{CH}_{2} \mathrm{Cl}_{2}: \mathrm{MeOH}$ (100:1, $50: 1,20: 1,10: 1,1: 1,0: 1 ; 3 \mathrm{~L}$ each). The resulting fractions from column chromatographic separation were combined into four fractions (A, $12 \mathrm{~g} ; \mathrm{B}, 10 \mathrm{~g} ; \mathrm{C}, 32 \mathrm{~g} ; \mathrm{D}, 12 \mathrm{~g}$ ) based on the TLC results. These four column fractions inhibited HNE by $32 \%, 38 \%$, $68 \%$, and $41 \%$, respectively, at $4 \mu \mathrm{g} / \mathrm{ml}$. In this bioassay-guided study, the most active column fraction, $\mathrm{C}$, was subjected to $\mathrm{YMC}$ RP-18 column chromatography $(50 \times 5 \mathrm{~cm})$ and eluted with a $\mathrm{MeOH}: \mathrm{H}_{2} \mathrm{O}$ gradient $(2: 3,1: 1,2: 1,4: 1 ; 1 \mathrm{~L}$ each) to afford three subfractions [C1 (1 L, $5.3 \mathrm{~g}), \mathrm{C} 2(1 \mathrm{~L}, 14.5 \mathrm{~g})$, and C3 (2 L, $4.8 \mathrm{~g})]$. Fraction $\mathrm{C} 1(5.0 \mathrm{~g})$ was subjected to further chromatography using a YMC RP-18 column $(50 \times 3 \mathrm{~cm})$ and a $\mathrm{MeOH}: \mathrm{H}_{2} \mathrm{O}$ gradient $(1: 1$, 2:1, 4:1; $1 \mathrm{~L}$ each) to obtain compounds 1 (39 $\mathrm{mg}$ ) and 2 (374 mg). Chromatography of fraction C2 (14.0 g) on a YMC RP-18 column $(50 \times 5 \mathrm{~cm})$ using a $\mathrm{MeOH}: \mathrm{H}_{2} \mathrm{O}$ gradient $(1: 1,2: 1,4: 1 ; 1 \mathrm{~L}$ each) afforded three subfractions [C2.1 (1 L, $3.2 \mathrm{~g}), \mathrm{C} 2.2(1 \mathrm{~L}, 5.5 \mathrm{~g})$, and C2.3 (1 L, $2.2 \mathrm{~g})]$, one of which, C2.2 $(5.0 \mathrm{~g})$, was further chromatographed on a YMC RP-18 column $(50 \times 3 \mathrm{~cm})$, eluting with a $\mathrm{MeOH}: \mathrm{H}_{2} \mathrm{O}$ gradient $(1: 1,2: 1,4: 1 ; 0.7 \mathrm{~L}$ each) to obtain compounds 3 (41 mg), 4 (65 mg), and 5 (21 mg). Fraction C3 (4.5 g) was chromatographed separately on a YMC RP-18 column $(50 \times 3 \mathrm{~cm})$, eluting with a $\mathrm{MeOH}: \mathrm{H}_{2} \mathrm{O}$ gradient $(1: 1,2: 1,4: 1 ; 1 \mathrm{~L}$ each), to yield compound $6(104 \mathrm{mg})$. The purity of the isolated compounds ranged from $95.0 \%$ to $99.4 \%$, as determined by analytical HPLC [Agilent 1200 HPLC system; Luna C18 column $(250 \times 4.6 \mathrm{~mm}, 5.0 \mu \mathrm{m})$, Phenomenex; 70\% acetonitrile in water; UV detection, $215 \mathrm{~nm}$; flow rate, $1.0 \mathrm{ml} / \mathrm{min}$ ].

Inulanolide E1 (1): white amorphous powder; $[\alpha]_{\mathrm{D}}^{25}+99.2(c 0.1$, $\left.\mathrm{CHCl}_{3}\right) ; \mathrm{UV}(\mathrm{MeOH}) \lambda_{\max } 202,235 \mathrm{~nm} ; \mathrm{ECD}\left(\mathrm{CHCl}_{3}\right) \lambda_{\max }(\Delta \varepsilon) 215$

Table 1. ${ }^{1} \mathrm{H}-(400 \mathrm{MHz})$ and ${ }^{13} \mathrm{C}-\mathrm{NMR}(100 \mathrm{MHz})$ data for $\mathbf{1}$ (in $\mathrm{CDCl}_{3}$ ).

\begin{tabular}{|c|c|c|}
\hline $\mathrm{C}$ & $\delta_{\mathrm{c}}$ & $\delta_{\mathrm{H}}(J$ in $\mathrm{Hz})$ \\
\hline 1 & $64.8 \mathrm{t}$ & $4.00 \mathrm{~m}, 3.98 \mathrm{~m}$ \\
\hline 2 & $27.1 \mathrm{t}$ & $1.60 \mathrm{~m}, 1.49 \mathrm{~m}$ \\
\hline 3 & $33.7 \mathrm{t}$ & $1.64 \mathrm{~m}, 1.62 \mathrm{~m}$ \\
\hline 4 & $34.7 \mathrm{~d}$ & $2.96 \mathrm{~m}$ \\
\hline 5 & $145.5 \mathrm{~s}$ & \\
\hline 6 & $124.6 \mathrm{~d}$ & $7.23 \mathrm{~d}(2.1)$ \\
\hline 7 & $139.8 \mathrm{~s}$ & \\
\hline 8 & $124.4 \mathrm{~d}$ & $7.14 \mathrm{dd}(8.0,2.1)$ \\
\hline 9 & $130.3 \mathrm{~d}$ & $7.06 \mathrm{~d}(8.0)$ \\
\hline 10 & $134.0 \mathrm{~s}$ & \\
\hline 11 & $60.6 \mathrm{~s}$ & \\
\hline 12 & $177.4 \mathrm{~s}$ & \\
\hline 13 & $42.9 \mathrm{~d}$ & $2.87 \mathrm{~m}, 2.34 \mathrm{~m}$ \\
\hline 14 & $19.2 \mathrm{q}$ & $2.27 \mathrm{~s}$ \\
\hline 15 & $21.8 \mathrm{q}$ & $1.21 \mathrm{~d}(5.6)$ \\
\hline $1^{\prime}$ & $61.3 \mathrm{~s}$ & \\
\hline $2^{\prime}$ & $82.0 \mathrm{~d}$ & $3.47 \mathrm{~d}(2.0)$ \\
\hline $3^{\prime}$ & $55.0 \mathrm{~d}$ & $3.75 \mathrm{~d}(2.0)$ \\
\hline $4^{\prime}$ & $135.5 \mathrm{~s}$ & \\
\hline $5^{\prime}$ & $139.1 \mathrm{~s}$ & \\
\hline $6^{\prime}$ & $26.2 \mathrm{t}$ & $2.08 \mathrm{~m}, 2.94 \mathrm{~m}$ \\
\hline $7^{\prime}$ & $45.9 \mathrm{~d}$ & $2.71 \mathrm{~m}$ \\
\hline $8^{\prime}$ & $82.5 \mathrm{~d}$ & $4.21 \mathrm{ddd}(12.0,9.0,3.2)$ \\
\hline $9^{\prime}$ & $36.1 \mathrm{t}$ & $2.10 \mathrm{~m}, 2.36 \mathrm{~m}$ \\
\hline $10^{\prime}$ & $29.9 \mathrm{~d}$ & $2.15 \mathrm{~m}$ \\
\hline $11^{\prime}$ & $139.7 \mathrm{~s}$ & \\
\hline $12^{\prime}$ & $170.3 \mathrm{~s}$ & \\
\hline $13^{\prime}$ & $119.4 \mathrm{t}$ & $6.24 \mathrm{~d}(3.2), 5.49 \mathrm{~d}(3.2)$ \\
\hline $14^{\prime}$ & $16.9 \mathrm{q}$ & $0.96 \mathrm{~d}(6.8)$ \\
\hline $15^{\prime}$ & $14.5 \mathrm{q}$ & $1.83 \mathrm{~s}$ \\
\hline $1^{\prime \prime}$ & $170.8 \mathrm{~s}$ & \\
\hline $2^{\prime \prime}$ & $20.4 \mathrm{q}$ & $1.20 \mathrm{~s}$ \\
\hline
\end{tabular}


(-3.8), $245(+1.0) \mathrm{nm}$; IR (KBr) $v_{\max } 3377,2973,1729,1710,1629$, $1381,1260,1067 \mathrm{~cm}^{-1} ;{ }^{1} \mathrm{H}$ - and ${ }^{13} \mathrm{C}-\mathrm{NMR}$, see Table 1; HRESIMS m/ $z 559.2672[\mathrm{M}+\mathrm{Na}]^{+}\left(\right.$calcd for $\left.\mathrm{C}_{32} \mathrm{H}_{40} \mathrm{O}_{7} \mathrm{Na}, 559.2671\right)$.

\section{HNE Inhibitory Assay}

HNE inhibitory activity was evaluated following a previously described procedure [15]. Briefly, 100- $\mu$ l reaction mixtures containing $10 \mathrm{mM}$ Tris- $\mathrm{HCl}$ buffer (pH 7.5), $1.0 \mathrm{mM}$ MeO-Suc-AlaAla-Pro-Val-p-nitroanilide (Sigma, USA), 0.18 U HNE (CalbioChem, USA), and various concentrations of sample were incubated in a 96-well plate for $1 \mathrm{~h}$ at $37^{\circ} \mathrm{C}$ in the dark. Each reaction was stopped by the addition of $100-\mu$ l soybean trypsin inhibitor $(0.2 \mathrm{mg} / \mathrm{ml}$; CalbioChem, USA), and the absorbance at $405 \mathrm{~nm}$ was immediately measured using a microplate reader. EGCG (99\% purity; Sigma, USA) was used as a positive control. Experiments were performed in triplicate. The $\mathrm{IC}_{50}$ was estimated from the least-squares regression line of the logarithmic concentration plotted against remaining activity using GraphPad 5.0 Prism software (GraphPad Software, Inc.).

\section{Kinetic Analysis}

A kinetic study was conducted in the same reaction medium in the presence of various concentrations of sample, at substrate concentrations ranging from 0.1 to $0.8 \mathrm{mM}$. Reactions were started by adding diluted substrate and were recorded every $2 \mathrm{~min}$ for $10 \mathrm{~min}$ at $37^{\circ} \mathrm{C}$. The maximum velocity $\left(V_{\max }\right)$ and Michaelis constant $\left(K_{\mathrm{m}}\right)$ were determined by means of Lineweaver-Burk plots. The inhibition constant $\left(K_{\mathrm{i}}\right)$ was calculated from the Dixon plot. Graphs were plotted using SigmaPlot 12.5 software (Systat Software, Inc.).

\section{Results}

HNE Inhibitory Activity of Solvent Fractions of the Flowers of I. britannica

To search for active compounds in the flowers of $I$. britannica, an EtOH extract of these flowers was systematically divided into three solvent fractions (n-hexane-, EtOAc-, and $n$-BuOH-soluble) (Fig. 1A) and their HNE inhibitory activities were evaluated. The EtOAc-soluble fraction exhibited the strongest activity $\left(\mathrm{IC}_{50}, 1.49 \mu \mathrm{g} / \mathrm{ml}\right)$, followed by $n$-BuOH- $\left(\mathrm{IC}_{50}, 3.42 \mu \mathrm{g} / \mathrm{ml}\right)$ and $n$-hexane-soluble fractions $\left(\mathrm{IC}_{50}, 6.01 \mu \mathrm{g} / \mathrm{ml}\right)$ (Fig. 1B).

\section{Structure Determination of the Isolated Compounds}

The EtOAc-soluble fraction, which exhibited the most potent activity, was subjected to a series of chromatographic separation steps guided by HNE inhibitory activity, leading to the isolation of compounds 1-6 (Fig. 2). Based on comparison of the physicochemical and spectral data of these compounds with those in the literature, five known compounds were identified: japonicone A (2) [16], japonicone
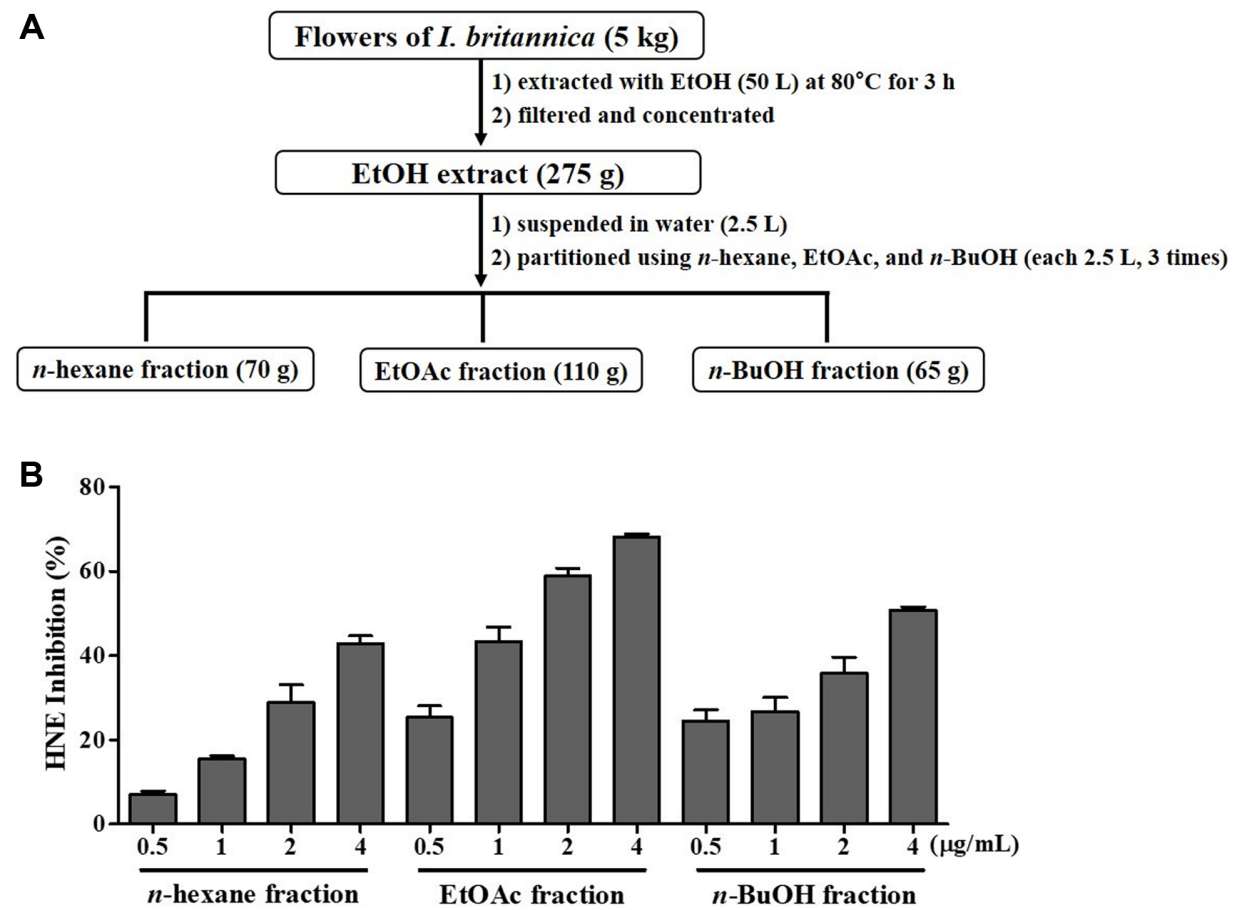

Fig. 1. Scheme of extraction and fractionation with different solvents of Inula britannica flowers (A) and HNE inhibitory activity of solvent fractions $(\mathbf{B})$. 


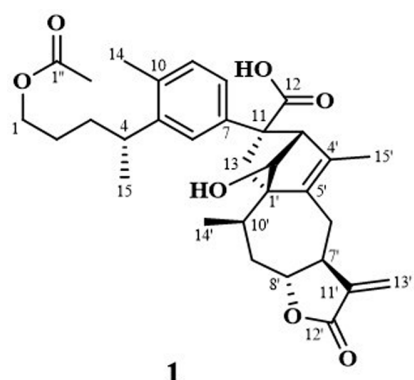

1

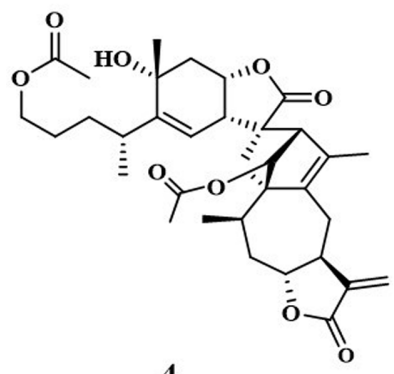

4
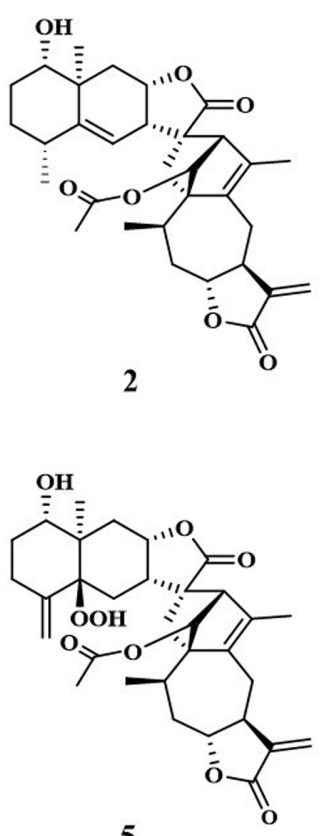
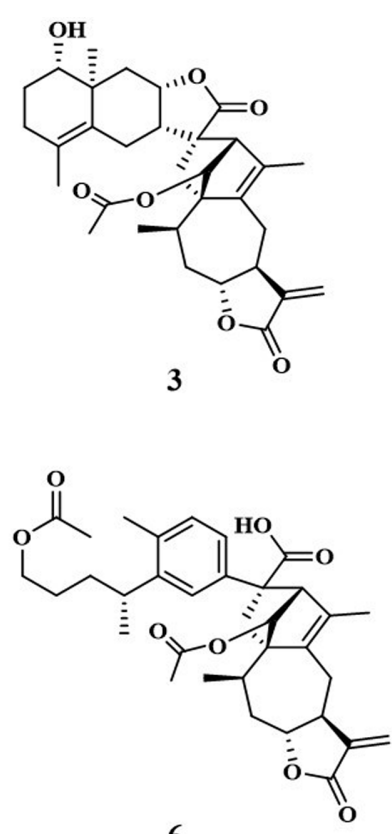

Fig. 2. Chemical structures of compounds 1-6 isolated from the flowers of I. britannica.

B (3) [16], japonicone D (4) [16], japonicone E (5) [17], and inulanolide E (6) [18].

Compound 1 was obtained as an amorphous white powder and showed a molecular ion peak at $m / z 559.2671$ $[\mathrm{M}+\mathrm{Na}]^{+}$in HRESIMS, establishing the molecular formula as $\mathrm{C}_{32} \mathrm{H}_{40} \mathrm{O}_{7}$. The IR spectrum showed characteristic absorption bands for carbonyls $\left(1,729\right.$ and $\left.1,710 \mathrm{~cm}^{-1}\right)$ and olefinic moieties $\left(1,629 \mathrm{~cm}^{-1}\right)$. The ${ }^{13} \mathrm{C}-\mathrm{NMR}$ data (Table 1$)$, combined with the DEPT data, indicated 32 carbon signals consisting of 5 methyls, 6 methylenes, 10 methines, 8 quaternary, and 3 carbonyl carbons, of which the signals at $\delta_{\mathrm{C}} 170.8$ and 20.4 were assigned to an acetoxy group; the remaining 30 carbon signals suggested that $\mathbf{1}$ is a dimeric sesquiterpene lactone consisting of two different sesquiterpene types, designated as units A and B. One of them was nearly identical to a guaianolide skeleton (unit B) [16-18], which was supported by the presence of an $\alpha$ methylene- $\gamma$-lactone functionality characterized by carbon signals at $\delta_{\mathrm{C}} 170.3\left(\mathrm{C}=\mathrm{O}, \mathrm{C}-12^{\prime}\right), 139.7$ and $119.4\left(\mathrm{C}=\mathrm{CH}_{2}, \mathrm{C}\right.$ $11^{\prime}$ and $\left.\mathrm{C}-13^{\prime}\right)$, and $82.5\left(\mathrm{C}-8^{\prime}\right)$, and also by the characteristic ${ }^{1} \mathrm{H}-\mathrm{NMR}$ data for an exocyclic methylene of $\mathrm{H}-13$ 'a and $\mathrm{H}-$ $13^{\prime} \mathrm{b}\left(\delta_{\mathrm{H}} 6.24\right.$ and 5.49 each $\left.\mathrm{d}, J=3.2 \mathrm{~Hz}\right)$ (Table 1$)$. The other unit (unit A) was assumed to be an eudesmane sesquiterpene with a seco-ring, according to a detailed analysis of various 2D NMR spectra, such as ${ }^{1} \mathrm{H}^{1}{ }^{1} \mathrm{H}$ COSY, HSQC, and HMBC. In the ${ }^{1} \mathrm{H}-\mathrm{NMR}$ spectrum, the characteristic signals for an $\mathrm{ABX}$ aromatic system at $\delta_{\mathrm{H}} 7.23(1 \mathrm{H}, \mathrm{d}, J=2.1 \mathrm{~Hz}, \mathrm{H}-6), 7.14$
$(1 \mathrm{H}, \mathrm{dd}, J=8.0,2.1 \mathrm{~Hz}, \mathrm{H}-8)$, and $7.06(1 \mathrm{H}, \mathrm{d}, J=8.0 \mathrm{~Hz}, \mathrm{H}-$ $9)$, an acetoxyl group at $\delta_{\mathrm{H}} 1.20\left(3 \mathrm{H}, \mathrm{s}, \mathrm{H}-2^{\prime \prime}\right)$, and the signals for a branched pentanol moiety, were observed. The presence of a branched pentanol moiety was supported by the ${ }^{1} \mathrm{H}-{ }^{1} \mathrm{H}$ COSY correlations observed between $\mathrm{H}_{2}-1 / \mathrm{H}_{2}-2$, $\mathrm{H}_{2}-2 / \mathrm{H}_{2}-3, \quad \mathrm{H}_{2}-3 / \mathrm{H}-4$, and $\mathrm{H}-4 / \mathrm{H}_{3}-15$ (Fig. $3 \mathrm{~A}$ ). The placement of this pentanol moiety on $\mathrm{C}-5$ was deduced from HMBC correlations among H-4/C-5, C-6, and C-10 (Fig. 3A). Furthermore, the HMBC correlations between $\mathrm{H}_{2}-1 / \mathrm{C}-1^{\prime \prime}$ and $\mathrm{H}-13 / \mathrm{C}-12$ indicated the presence of a methyl ester group at $\mathrm{C}-1$ and a carboxyl group at C-11. The linkage between the two units, via two C-C single bonds between $\mathrm{C}-13 / \mathrm{C}-1^{\prime}$ and $\mathrm{C}-11 / \mathrm{C}-3^{\prime}$, was deduced from the key HMBC correlations among $\mathrm{H}-2^{\prime} / \mathrm{C}-1^{\prime}, \mathrm{C}-11$, and C-13; $\mathrm{H}-3^{\prime} / \mathrm{C}-7, \mathrm{C}-11$, and C-13; and between $\mathrm{H}_{2}-13 / \mathrm{C}-$ 11, C-1' and C-5' (Fig. 3A). Detailed comparison of these spectral data with those of reported sesquiterpenes isolated from this plant revealed that the ${ }^{1} \mathrm{H}$ - and ${ }^{13} \mathrm{C}-\mathrm{NMR}$ data of $\mathbf{1}$ were very similar to those of inulanolide E (6) [18], except for the additional signals consistent with the presence of an oxygenated methine group $\left[\delta_{\mathrm{H}} 3.47, \mathrm{~d}, J=2.0 \mathrm{~Hz} ; \delta_{\mathrm{C}} 82.0\right.$ (d)] instead of an acetoxy group at C-2' in 6. The position of a hydroxyl group at $\mathrm{C}-2^{\prime}$ was further supported by the ${ }^{1} \mathrm{H}$ ${ }^{1} \mathrm{H}$ COSY correlation of $\mathrm{H}-2^{\prime} / \mathrm{H}-3^{\prime}$, as well as the HMBC correlations among H-2'/C-1', C-3', C-11, and C-13 (Fig. 3A).

The relative configuration of 1 was determined on the basis of a NOESY experiment and a comparison of the 
A

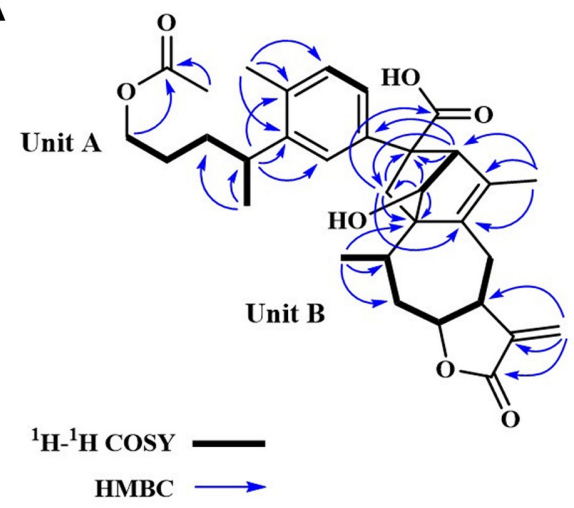

B

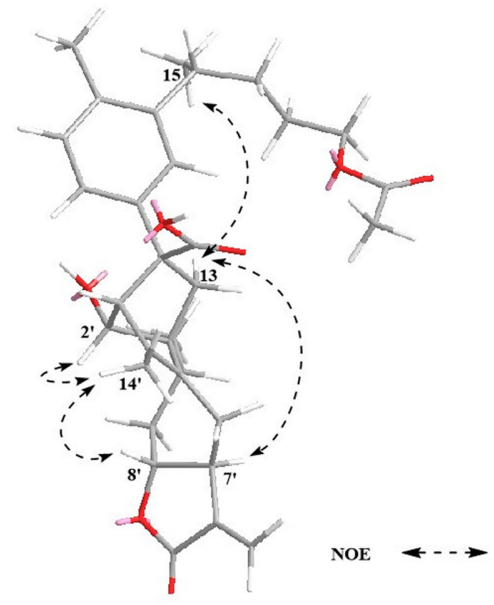

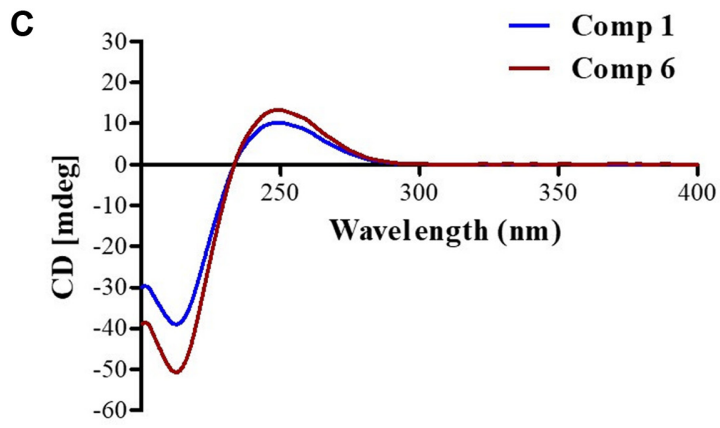

Fig. 3. Structure elucidation of compound 1 .

Key ${ }^{1} \mathrm{H}-{ }^{1} \mathrm{H}$ COSY and HMBC correlations (A), key NOE correlations (B), and ECD spectrum of $\mathbf{1}$ and $\mathbf{6}(\mathbf{C})$.

coupling constants with the literature. The large coupling constant between $\mathrm{H}-\mathrm{7}^{\prime}$ and $\mathrm{H}-8^{\prime}(J=12.0 \mathrm{~Hz})$ suggested a trans-fused guaianolide skeleton $[17,19]$. The orientation of the C-15 and C-14' methyl groups was assigned as $\alpha$ and $\beta$, respectively, from the NOE correlations observed between $\mathrm{H}-\mathrm{7}^{\prime} / \mathrm{H}_{2}-13$ and $\mathrm{H}_{2}-13 / \mathrm{H}_{3}-15$ and $\mathrm{H}-2^{\prime} / \mathrm{H}_{3}-14^{\prime}$ and $\mathrm{H}-8^{\prime} /$ $\mathrm{H}_{3}-14^{\prime}$ (Fig. 3B). In the electronic circular dichroism (ECD) spectrum of 1 , a negative Cotton effect appeared at around $215 \mathrm{~nm}$, while a positive Cotton effect was observed around $245 \mathrm{~nm}$. This ECD feature was identical to those of 6 (Fig. 3C) and japonicones U and V [20], indicating that these compounds possessed the same absolute configuration. The absolute configuration of $\mathbf{1}$ was therefore assigned to be $4 R, 11 S, 1^{\prime} R, 2^{\prime} R, 3^{\prime} S, 7^{\prime} S, 8^{\prime} R, 10^{\prime} R$. Finally, the structure of 1 was established as depicted in Fig. 2, and it was named inulanolide E1.

\section{HNE Inhibitory Activity of the Isolated Compounds}

The inhibitory activities of the isolated compounds (1-6) on HNE were evaluated in vitro according to a procedure described previously [15]. As shown in Table 2, all tested compounds except for 2 and 4 exhibited significant inhibitory effects against $\mathrm{HNE}$ activity, with $\mathrm{IC}_{50}$ values ranging from 8.2 to $42.5 \mu \mathrm{M}$. Among the compounds tested,

Table 2. HNE inhibitory effects of compounds 1-6 from the flowers of I. britannica.

\begin{tabular}{cll}
\hline Compounds & $\mathrm{IC}_{50}(95 \% \mathrm{CI}) \mu \mathrm{M}^{\mathrm{a}}$ & Inhibition mode $\left(K_{\mathrm{i}}^{\mathrm{b}}, \mu \mathrm{M}\right)$ \\
\hline $\mathbf{1}$ & $8.2(7.2-9.2)$ & Noncompetitive $(8.0)$ \\
$\mathbf{2}$ & $>100$ & $\mathrm{NT}^{\mathrm{c}}$ \\
$\mathbf{3}$ & $21.9(20.2-23.8)$ & Noncompetitive $(22.8)$ \\
$\mathbf{4}$ & $>100$ & $\mathrm{NT}$ \\
$\mathbf{5}$ & $42.5(36.0-49.1)$ & $\mathrm{NT}$ \\
$\mathbf{6}$ & $10.4(9.4-11.4)$ & $\mathrm{NT}$ \\
EGCG $^{\mathrm{d}}$ & $10.9(10.3-11.5)$ & $\mathrm{NT}$ \\
\hline
\end{tabular}

${ }^{a} \mathrm{IC}_{50}$ indicates the concentration $(\mu \mathrm{M})$ at which the inhibition percentage of the enzyme was $50 \%$, and values in the parentheses represent the $95 \%$ confidence intervals of the $\mathrm{IC}_{50}$ values.

${ }^{b}$ Values of inhibition constant.

${ }^{\mathrm{c}} \mathrm{NT}$ is not tested.

${ }^{\mathrm{d}}$ Epigallocatechin gallate (EGCG) was used as a positive control. 

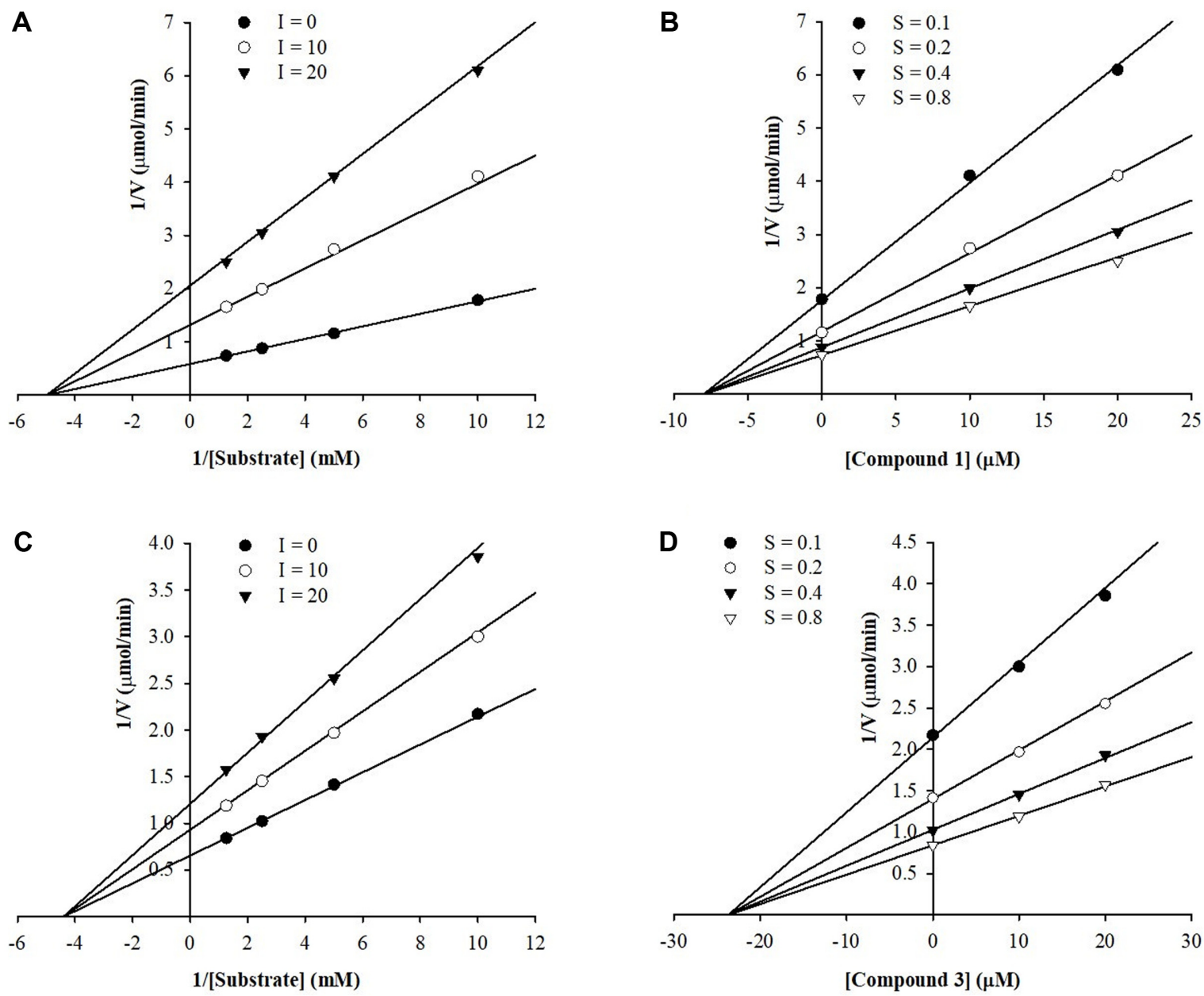

Fig. 4. Kinetic studies on HNE inhibition by compounds 1 and 3.

Double-reciprocal Lineweaver-Burk plots of $\mathbf{1}(\mathbf{A})$ and $\mathbf{3}(\mathrm{C})$. The concentrations of $\mathbf{1}$ and $\mathbf{3}$ were 0

$(\mathbf{B})$ and $3(\mathbf{D})$. The concentrations of substrate were $0.1(\mathbf{O}), 0.2(\bigcirc), 0.4(\boldsymbol{\nabla})$, and $0.8 \mathrm{mM}(\nabla)$.

inulanolide E1 (1) exhibited the most potent HNE inhibitory activity with an $\mathrm{IC}_{50}$ value of $8.2 \mu \mathrm{M}$, comparable to that of epigallocatechin gallate (EGCG; $\left.\mathrm{IC}_{50}=10.9 \mu \mathrm{M}\right)$. Inulanolide $\mathrm{E}(6)$, which differs from 1 only in the substituent on $\mathrm{C}-2^{\prime}$, also showed considerable HNE inhibitory activity $\left(\mathrm{IC}_{50}=\right.$ $10.4 \mu \mathrm{M})$. In addition, japonicone B (3) and japonicone E (5) exhibited moderate HNE inhibition, with $\mathrm{IC}_{50}$ values of 21.9 and $42.5 \mu \mathrm{M}$, respectively.

Kinetic Studies on HNE Inhibition by Compounds 1 and 3

To further characterize the HNE inhibitory behavior of the isolates, an enzymatic kinetic study was performed over a series of concentrations of two potent inhibitors (1 and 3) with different structural features and substrates. Under the experimental conditions, the oxidation of HNE by 1 and 3 followed Michaelis-Menten kinetics. As shown by the Lineweaver-Burk plot (Figs. $4 \mathrm{~A}$ and $4 \mathrm{C}$ ), the $\mathrm{x}$ intercept $\left(-1 / K_{\mathrm{m}}\right)$ was unaffected by increasing concentrations of 1 and 3 (from 0 to $20 \mu \mathrm{M}$ ), whereas $1 / V_{\max }$ increased gradually. Therefore, the mechanism by which $\mathbf{1}$ and $\mathbf{3}$ inhibited HNE was noncompetitive inhibition. Moreover, the Dixon plot analysis indicated that the inhibition constant $\left(K_{\mathrm{i}}\right)$ values of $\mathbf{1}$ and 3 were 8.0 and $22.8 \mu \mathrm{M}$, respectively (Figs. 4B and 4D, Table 2).

\section{Discussion}

HNE (E.C. 3.4.21.37) is a member of the chymotrypsin family of serine proteases primarily found in the azurophilic granules of neutrophils. It has broad substrate specificity and can degrade not only elastin, but also a variety of extracellular matrix proteins such as fibronectin, laminin, 
collagen, and proteoglycans [21]. Under normal physiological conditions, HNE activity is tightly regulated by its endogenous protease inhibitors, such as secretory leukocyte protease and $\alpha 1$-protease inhibitors [22]. However, large amounts of oxygen radicals and proteases released by leukocytes that are recruited to sites of inflammation can overwhelm and inactivate these endogenous inhibitors [23]. This imbalance between HNE and its endogenous inhibitors can lead to abnormal degradation of healthy tissue, resulting in the development of chronic inflammatory diseases, such as rheumatoid arthritis, pulmonary emphysema, adult respiratory distress syndrome, cystic fibrosis, and delayed wound healing. Thus, the development and investigation of HNE inhibitors, particularly natural anti-HNE agents without side effects, may constitute a therapeutic approach for the prevention and treatment of inflammation-related diseases.

The present study was undertaken to identify natural products that inhibit HNE and revealed that I. britannica flowers are a potent HNE inhibitor. Thus, we propose I. britannica flowers as a new candidate for anti-HNE agents. We isolated six sesquiterpene lactone dimers, one of which is novel, as active compounds from this plant. Sesquiterpene lactones are an important class of compounds produced by many plants with a broad range of biological activities. Although sesquiterpene lactone monomers have been reported to exhibit HNE inhibitory activity [24-26], the HNE-inhibiting properties of the dimeric forms are reported here for the first time. Our findings suggest that the flowers of I. britannica and its active sesquiterpene lactone dimers would be an excellent source of natural HNE inhibitors for cosmetic and medicinal uses.

\section{Acknowledgments}

This work was supported by a grant from the Technology/ R\&D project, Small and Medium Business Administration, Republic of Korea (SMBA-2016-S2410418). The NMR and MS experiments were performed by the Korea Basic Science Institute (KBSI).

\section{Conflict of Interest}

The authors have no financial conflicts of interest to declare.

\section{References}

1. Lin R, Yu DJ, Wu ZY. 1989. Flora of China, pp. 263-265.
Beijing, Science Press.

2. Bai N, Zhou Z, Zhu N, Zhang L, Quan Z, He K, et al. 2005. Antioxidative flavonoids from the flower of Inula Britannica. J. Food Lipids 12: 141-149.

3. Zhao YM, Zhang ML, Shi QW, Kiyota H. 2006. Chemical constituents of plants from the genus Inula. Chem. Biodivers 3: 371-384.

4. Tang SA, Zhu H, Qin N, Zhou JY, Lee E, Kong DX, et al. 2014. Anti-inflammatory terpenes from flowers of Inula japonica. Planta Med. 80: 583-589.

5. Lee N, Lee J, Lee YJ, Ahn SH, Eom SJ, Paik H. 2013. Antimicrobial effect of Inula britannica flower extract against methicillin-resistant Staphylococcus aureus. Korean J. Microbiol. Biotechnol. 41: 335-340.

6. Song QH, Kobayashi T, Iijima K, Hong T, Cyong JC. 2000. Hepatoprotective effects of Inula britannica on hepatic injury in mice. Phytother. Res. 14: 180-186.

7. Kobayashi T, Song QH, Hong T, Kitamura H, Cyong JC. 2002. Preventative effects of the flowers of Inula britannica on autoimmune diabetes in C57BL/KsJ mice induced by multiple low doses of streptozotocin. Phytother. Res. 16: 377382.

8. Shan JJ, Yang M, Ren JW. 2006. Anti-diabetic and hypolipidemic effects of aqueous-extract from the flower of Inula japonica in alloxan-induced diabetic mice. Biol. Pharm. Bull. 29: 455-459.

9. Wang CM, Jia ZJ, Zheng RL. 2007. The effect of 17 sesquiterpenes on cell viability and telomerase activity in the human ovarian cancer cell line HO-8910. Planta Med. 73: 180-184.

10. Jin HZ, Lee D, Lee JH, Lee K, Hong YS, Choung DH, et al. 2006. New sesquiterpene dimers from Inula britannica inhibit NF- $\kappa \mathrm{B}$ activation and NO and TNF- $\alpha$ production in LPSstimulated RAW264.7 cells. Planta Med. 72: 40-45.

11. Khan AL, Hussain J, Hamayun M, Gilani SA, Ahmad S, Rehman G, et al. 2010. Secondary metabolites from Inula britannica L. and their biological activities. Molecules 15: 1562-1577.

12. Pan MH, Chiou Y, Cheng AC, Bai N, Lo CY, Tan D, et al. 2007. Involvement of MAPK, Bcl-2 family, cytochrome-c, and caspases in induction of apoptosis by 1,6-O,Odiacetylbritannilactone in human leukemia cells. Mol. Nut. Food Res. 51: 229-238.

13. Seca AML, Grigore A, Pinto DCGA, Silva AMS. 2014. The genus Inula and their metabolites: from ethnopharmacological to medicinal uses. J. Ethnopharmacol. 154: 286-310.

14. Wang GW, Qin JJ, Cheng XR, Shen YH, Shan L, Jin HZ, et al. 2014. Inula sesquiterpenoids: structural diversity, cytotoxicity and anti-tumor activity. Expert. Opin. Investing Drugs 23: 317-345.

15. Kim YH, Ryoo IJ, Choo SJ, Xu GH, Seok SJ, Bae K, et al. 2009. Clitocybin D, a novel human neutrophil elastase inhibitor from the culture broth of Clitocybe aurantiaca. J. 
Microbiol. Biotechnol. 19: 1139-1141.

16. Qin JJ, Jin HZ, Fu JJ, Hu XJ, Wang Y, Yan SK, et al. 2009. Japonicones A-D, bioactive dimeric sesquiterpenes from Inula japonica Thunb. Bioorg. Med. Chem. Lett. 19: 710-713.

17. Qin JJ, Jin HZ, Zhu JX, Fu JJ, Hu XJ, Liu XH, et al. 2010. Japonicones $\mathrm{E}-\mathrm{L}$, dimeric sesquiterpene lactones from Inula japonica Thunb. Planta Med. 76: 278-283.

18. Xu XY, Sun P, Guo DA, Liu X, Liu JH, Hu LH. 2015. Cytotoxic sesquiterpene lactone dimers isolated from Inula japonica. Fitoterapia 101: 218-223.

19. Qin JJ, Wang LY, Zhu JX, Jin HZ, Fu JJ, Liu XF, et al. 2011. Neojaponicone A, a bioactive sesquiterpene lactone dimer with an unprecedented carbon skeleton from Inula japonica. Chem. Commun. 47: 1222-1224.

20. Xie C, Wang H, Sun X, Meng L, Wang M, Bartlam M, et al. 2015. Isolation, characterization, and antiproliferative activities of eudesmanolide derivatives from the flowers of Inula japonica. J. Agric. Food Chem. 63: 9006-9011.

21. Steinbrecher T, Herenn A, Dormann KL, Merfort I, Labahn A.
2008. Bornyl (3,4,5-trihydroxy)-cinnamate - An optimized human neutrophil elastase inhibitor designed by free energy calculations. Bioorg. Med. Chem. 16: 2385-2390.

22. Williams SE, Brown TI, Roghanian A, Sallenave JM. 2006. SLPI and elafin: one glove, many fingers. Clin. Sci. 110: 21-35.

23. Clark RA, Stone PJ, El Hag A, Calore JD, Franzblau C. 1981. Myeloperoxidase-catalyzed inactivation of alpha 1-protease inhibitor by human neutrophils. J. Biol. Chem. 256: 3348-3353.

24. Siedle B, Cisielski S, Murillo R, Löser B, Castro V, Klaas CA, et al. 2002. Sesquiterpene lactones as inhibitors of human neutrophil elastase. Bioorg. Med. Chem. 10: 2855-2861.

25. Siedle B, Gustavsson L, Johansson S, Murillo R, Castro V, Bohlin L, et al. 2003. The effect of sesquiterpene lactones on the release of human neutrophil elastase. Biochem. Pharmacol. 65: 897-903.

26. Siedle B, Hrenn A, Merfort I. 2007. Natural compounds as inhibitors of human neutrophil elastase. Planta Med. 73: 401420 . 